\title{
INVESTIGATION OF MOBILE AUGMENTED REALITY APPLICATIONS USED IN THE INTERIOR DESIGN
}

\author{
Tolga KILIÇ \\ Mimar Sinan Fine Arts University, Turkey \\ http://orcid.org/0000-0003-1727-6022 \\ tolga.kilic@msgsu.edu.tr
}

\begin{abstract}
Scientific developments have triggered bleeding-edge technologies that have positive effect on the life-quality of human-beings. One of these technologies is named as Augmented Reality (AR) which also the thesis has focused on. The AR technology is defined as the mixture of reality and virtuality. The AR technology that based on the combination of real space and/or object along with the virtual object within the same platform, has aimed at getting more information for the interactive users about the objects interacted with. AR applications can now experience a widespread deployment of mobile smart devices and a large kit kit. This study aims to discuss the use of a new technique, AR technology, as a tool in the representation and experience of interior space and the effects of user experience on the activities of mobile indoor AR applications. For this purpose, we reviewed Android and IOS-based seven mobile interiors AR applications by searching for 'augmented reality interior design' on Google Play and Apple Store mobile stores as of February 2018. Therefore, both design and designers and end users have tried to determine the use of these applications and their identified deficiencies. In the future, AR is considered to be a powerful influence on the interior designer and user axis, and is considered as a new technique and strategy that will contribute to the transformation of the space concept into technology coexistence. The AR technologies, to be deemed as having strong effect within the framework of interior designer and user, are evaluated as a new technique and strategy that will make a significant contribution to the transformation of space concept in line with the developing technologies.
\end{abstract}

Keywords: Interior Space, Augmented Reality, 3D Interaction, Mobility.

\section{MOBILL ARTIRILMIŞ GERÇEKLIK UYGULAMALARININ İÇ TASARIMDA KULLANILMASININ INCELENMESI}

\section{ÖZ}

Bilimsel gelişmeler, insanoğlunun yaşam kalitesi üzerinde olumlu etkisi olan teknolojiyi tetiklemiştir. $\mathrm{Bu}$ teknolojilerden biri de, tezin üzerinde durduğu Artırılmış Gerçeklik (AR) olgusudur. AR teknolojisi gerçeklik ve sanallığın karışımı olarak tanımlanır. Aynı platformdaki sanal nesne ile birlikte gerçek alan ve / veya nesnenin kombinasyonuna dayanan AR teknolojisi, etkileşimli kullanıcılar hakkında daha fazla bilgi edinmeyi amaçlamıştır. AR uygulamaları artık mobil akıllı cihazların uygulamalarında deneyimlenebilir. Bu çalışma, yeni bir teknik olan AR teknolojisinin iç mekan temsili ve deneyiminde bir araç olarak kullanılmasını ve kullanıcı deneyiminin mobil iç mekan AR uygulamalarının faaliyetleri üzerindeki etkilerini tartışmayı amaçlamaktadır. Bu amaçla, Google Play ve Apple Store mobil mağazalarında Şubat 2018'den itibaren 'artırılmış gerçeklik iç tasarımı' için arama yaparak Android ve IOS tabanlı yedi mobil iç mekan AR uygulamaları incelenmiş̧ir. Bu nedenle, hem tasarım hem de tasarımcılar ve son kullanıcılar bu uygulamaların kullanımını ve tespit edilen eksikliklerini belirler. Gelecekte, artırılmış gerçeklik, iç mimar ve kullanıcı ekseni üzerinde güçlü bir etki olarak kabul edilir ve uzay konseptinin teknoloji bir arada yaşama dönüşümüne katkıda 
bulunacak yeni bir teknik ve strateji olarak kabul edilir. İç mimar ve kullanıcı çerçevesinde güçlü etkiye sahip olduğu düşünülen AR teknolojileri, gelişen konseptler doğrultusunda mekan kavramının dönüşümüne önemli katkı sağlayacak yeni bir teknik ve strateji olarak değerlendirilmektedir.

Anahtar Kelimeler: İç Mekan, Artırılmış Gerçeklik, 3B Etkileşim, Hareketlilik.

\section{INTRODUCTION}

As in many fields of design, interior design and space representation (presentation) are also utilized in technological applications. Augmented Reality (AR) technology is also considered as one of the new applications that affect interior design and experience. Through an intelligent mobile device with AR technology, users can view three-dimensional virtual objects in real physical surroundings. Thus, users can make a realistic assessment by experiencing the different models and features of the equipment that are not present in the space in the actual physical environment they are in. It is understood that many mobile AR applications based on Android and IOS are involved in virtual markets to serve similar purposes in different areas of use. Because of the diversity of these applications in terms of type, function, purpose, interface and user benefits, it is necessary to examine such applications for their use in interior design.

Study; it is aimed to strengthen the spatial perceptions of the users and to enable the designers to benefit more effectively from the AR applications by contributing to the development of the AR applications which are expected to have a more important place in the interior design and representation in the future. Study; 'The mobile AR applications used for indoor settlement have a positive effect on the strengthening of users' spatial perception and design preferences because they give near realistic results in the representation of space.' It was developed based on hypothesis.

Based on this hypothesis, research questions were made about working. These are;

- What are the strengths and weaknesses of existing mobile indoor AR applications?

- What might be the contribution of users to the experience and perception of the space in the development of mobile indoor AR applications?

- How can these applications be developed in order to benefit more from mobile indoor AR applications in the future?

The research universe has been identified as 'Apple Store' for IOS and 'Google Play' stores for Android. The study was limited to applications published between April 2016 and February 2018 in order to obtain reliable data depending on the size of the research area, the multi-layer structure spreading over various fields, and the reasons for the development of new applications during the research. The sample of the study is; android and IOS-based mobile AR applications with visual markers or markers with virtual furniture models designed for indoor use. AR applications that allow the display of architectural structures and / or plan-based projects are excluded from the scope of work because they do not allow for intervention in interior spaces. The evaluation criteria of the applications planned to be researched were developed in accordance with the mind mapping method obtained as a result of a field study conducted in 2013 by Sanni Siltanen et al. In the study, the applications used in interior design were determined quantitatively. Qualitative analysis was carried out after considering the characteristics of the applications determined by the researcher. It is planned that the research process in the study will be carried out causally / comparatively on the axes of the qualitative characteristics of the determined applications. 


\section{METHOD}

The study focuses on the identification of android and IOS-based indoor mobile AR applications in virtual markets, assessed from an end-user perspective and identified deficiencies. Consequently; it is aimed to contribute to the development of mobile AR applications, which are expected to have an important place in future in interior design and representation. Strengthening the spatial perceptions of users and designers is the ultimate goal of helping designers and users to maximize the benefits of AR applications.

In the research, 'Apple Store' for IOS based devices and 'Google Play' virtual stores for Android based devices were scanned using 'augmented reality intrior design' using descriptive scanning method. As a result of the scanning, seven indoor AR applications which have reached at least 1000 download score from these stores has been determined and downloaded. These applications, which were downloaded in the next period, have been tested and classified on both platforms. The classification criteria of the applications were determined by Sanni Siltanen et al., Based on the mental mapping method obtained as a result of a field study conducted in 2013 .

Siltanen and his colleagues conducted a field study to develop interior AR applications in the context of user needs and expectations. In this study, which consists of two groups of professional (interior architect) and normal users, it was aimed to determine the expectations of different user types from an internal architecture AR application. At the end of the study, professional users and normal users conveyed different and similar expectations about the application of an indoor AR. As a result of this research, a mind map has been created that collects the features users expect from an AR application. This mind map is seen in Table 1.2 (Siltanen, 2015). According to this mind map, red flags represent the first priority features in application and orange flags represent the second priority needs. Other needs include features that can vary. It should be remembered that these properties may change depending on future technological developments. The criteria used in the study were determined as an option to perform spatial modeling, user interface, virtual size, color and texture intervention, photo realism, interaction with existing furniture, trademark support, social media sharing feature and work. All these criteria are shown on a table together with the currently available applications and the effectiveness of the existing AR applications is expressed on a table. The table is shown in Table 1.2.

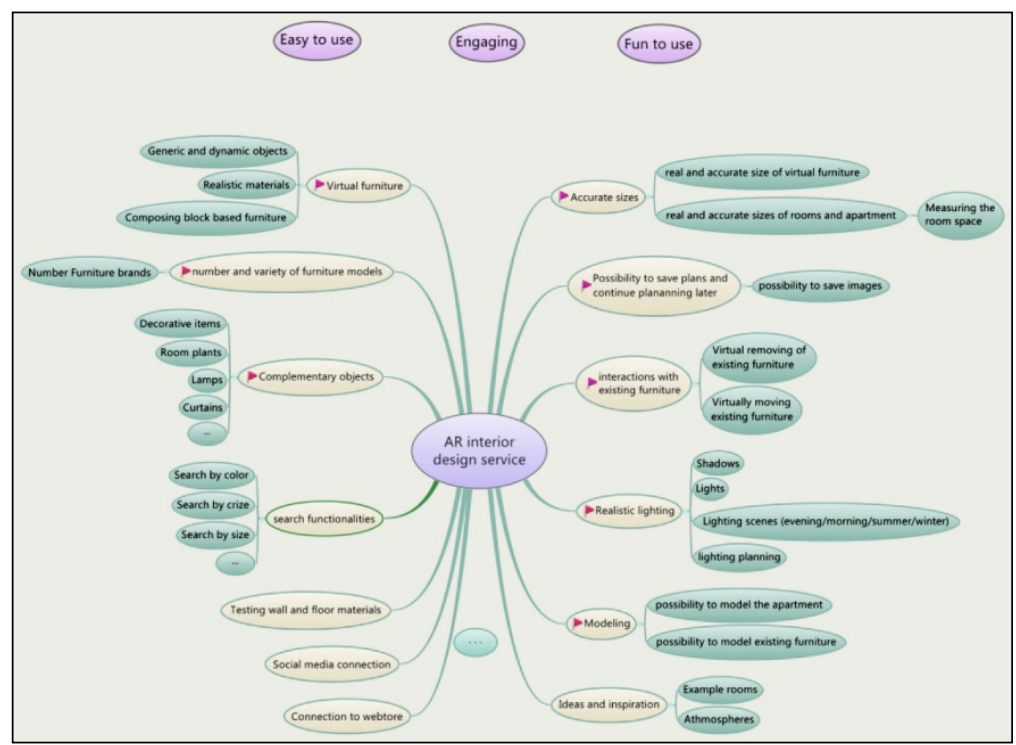

Table 1.2. A scheme that includes the expectations of professional designers and end users of an interior architecture AR. (Siltanen, 2015) 


\section{General Description And Concepts}

The AR and Mobile AR technology in the focus of this section is explained and general definitions are given. AR technology has been defined by making the differences from similar technologies. In the next section, a new platform, Mobil AR system, is given. The issue has been addressed in a multifaceted way by addressing the positive and negative aspects of mobile AR.

\subsection{Augmented Reality}

As a technology consulting firm that makes predictions about the future of emerging technological trends, Gartner reports the technology of AR as an emerging and promising technology since 2005. This "Hype Cycle" chart, published every year by Gartner, contains predictions about the market dynamics and the future of new technologies that are of global interest. According to the forecast published by the firm in 2017, AR is a technology that keeps on developing and approaches the threshold of productivity (URL-1, 2017).

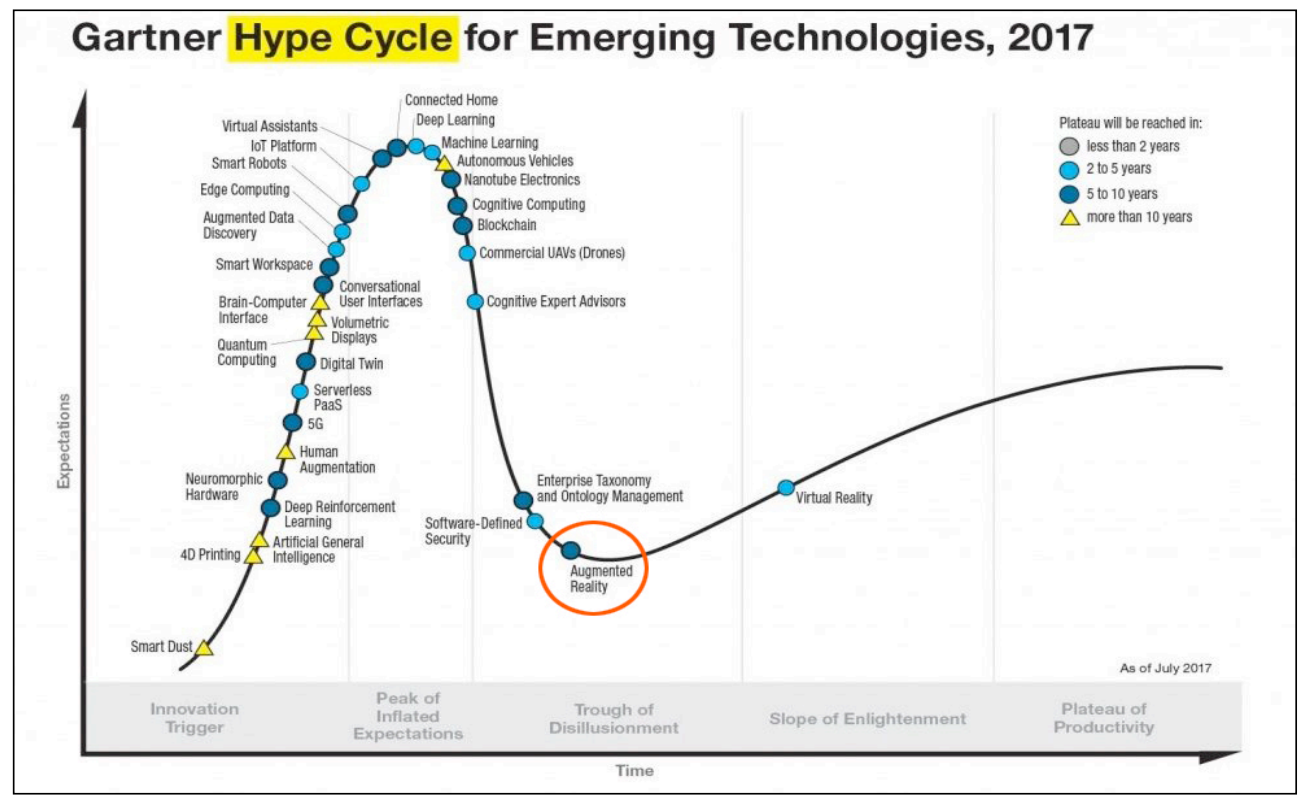

Figure 1. The position of AR technology in Gartner's Hype Cycle. (URL-1, 2017).

According to Ronald Azuma, who is considered one of the leading researchers of AR technology, AR is a variation of virtual environment or virtual reality (VR) (Azuma, 1997). Applications developed with SG technology can cause users to perceive the virtual environment as close to reality and concentrate fully on it, resulting in a certain period of disconnection from the real world. Thanks to VR technology, the user who focuses on the virtual world can not see the changes in the real world for a certain period of time. On the other hand, in AR technology, the user can perceive the real world. In this technology, virtual objects are superimposed on a real world defined region and / or the virtual physical environment is merged with the virtual object. According to Azuma, the AR technology that enables this merger should have three features.

- To combine truth and virtue,

- Providing real-time interaction,

- Having the ability to represent in three dimensions (3D) (Azuma, 1997). 
Some researchers working on AR have made definitions that limit AR only to a single technology such as HMD (Head-up Display). Despite these definitions Azuma Stated that HMD could be regarded as a basic AR component, but not limited to only this equipment, and other technologies have the potential to contribute to AR (Azuma, 1997).

AR means a living view of the physical reality world (Furth, 2011). This vitality can be expressed as a hybridization obtained by combining the computer generated virtual objects with reality.

In the course of the development of AR and VR, Paul Milgram and his colleagues introduced the idea of 'Reality-Virtuality Continuum Diagram' (Milgram et al., 1994), which is referenced by many researchers who have worked on both topics. This diagram, shown in Table 1.1, refers to the ongoing process of interaction between the real environment and the virtual environment. When the diagram is examined, it can be seen that AR and AV (Augmented Virtuality) definitions exist between reality and virtuality. According to this; It can be said that the AV concept is closer to reality than the real environment. According to the approach of Milgram et al. the user is experiencing the real world with all his sensory abilities only in the real environment, which is bound to the rules of physics. The virtual environment represents completely digital based spaces and objects, where there are no properties such as time, space and gravity.

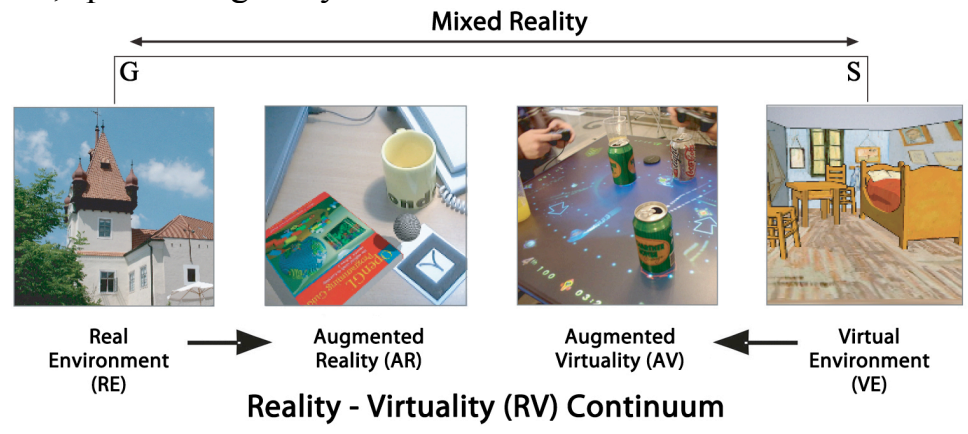

Figure 1.2. The relationship between reality and the virtual world It describes. (Milgram et al., 1994)

Because the virtual environment points to a world where only abstract data exist. According to diagram; while the concept of AR is formed by blending computer-generated information with real space or objects (Milgram et al., 1994). For this reason, the user can interact with both real and virtual data at the same time. At the same time, depending on the source of the data the user focuses on, the environment in which they think they can be changed. For this reason, a user who has experienced the virtual environment can disconnect the real environment and the connection for a certain period of time. According to this, the AR can be achieved only by virtue of being virtual or from reality. From the definitions mentioned, the way out of AR; it is possible to define it as a platform where virtuality can be experienced in reality.

\subsection{Mobil Augmented Reality}

AR technologies have undergone technological changes from the end of the 60 's, which began to develop, to day-to-day. As a result of these changes, the AR system components became more compact, which led to the emergence of mobile AR systems. Fixed or static AR systems used in public spaces or via large screens of desktop computers are generally only available in one location (Luckin et al., 2011). On the contrary, mobile systems that offer user mobility expand the field of productivity for the AR platform. Movement freedom adds new elements to AR. The most important of these elements is to encourage the mobility of the users, to increase the number of physical places that the learners can realize, to bridge between these places and to activate the links between formal and informal learning. (FitzGerald et al., 2013). 

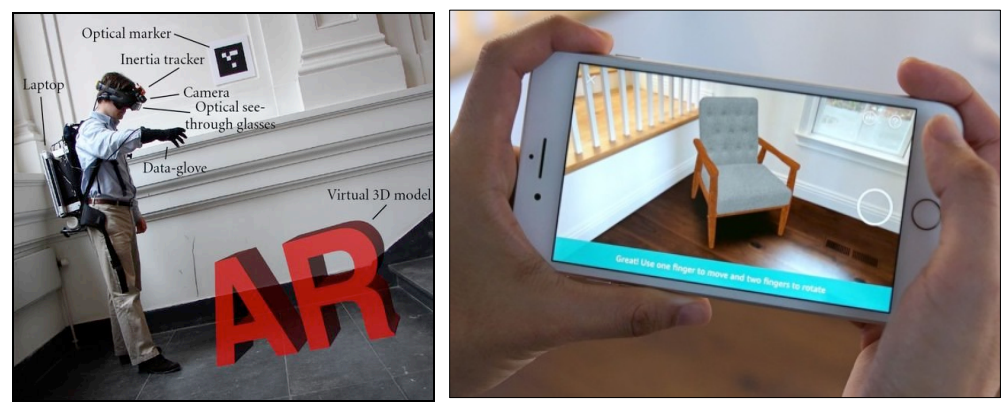

Figure 1.2. Two examples to the Mobile AR System

1. A Mobile-based System with a computer base (Caarls et al., 2009). 2. IOS based Mobile AR System (URL-2)

Mobile AR is helping users to use the right facilities in terms of time and space. Mobile AR allows to us for integrate experience and knowledge in specific contexts. (Cowan \& amp; Butler, 2013). By incorporating AR applications into smart devices, end users have been able to gain AR experience. Due to this increasing popularity of smartphones, AR has become a commodity that is everywhere for leisure and mobile learning. (Marcus et al., 2011).

A mobile AR system should be a device with a technical capacity that can be easily carried and used for targeted tasks. This, of course, means that the hardware components also provide this flexibility. Today's smartphones have components such as GPS (Global Positioning System), camera, accelerometer and processors with high processing capability. Today, mobile devices are usually manufactured with a number of basic sensors (Marcus et al., 2011). For this reason, applications with data processing and connectivity to servers can be run by similar devices. Likewise, smart tablets are also in the category of mobile AR devices because they can easily be moved to the desired location.

Another reason why mobile devices are suitable for AR is that they are cheaper and more accessible than computer systems. As these devices have the necessary technical equipment for a normal AR application, no other computer is needed.

\subsubsection{Diminished Reality}

The main use of AR application is to allow visualization without any physical effort. However, during visualization, objects located at the place where the virtual object will settle are a problem for AR processing. Therefore, it is necessary to solve this problem with a software.

One possible technique that can be used to solve this problem is the "diminished reality" technique. The capabilities of the diminished reality technique in terms of use in interior design are particularly valuable (Seppa et al., 2007).

In a visual repair process, "inpainting" (repair of a lost or damaged part of a visual) is used. This can be done with the parts to be added from the outside or the transfer of the remaining healthy areas of the visual to the damaged area. Increased reality researchers use this term in the same context as "reduce", "reduced reality", "object hiding" and "object losing". In Figure 1.4., a diminished reality technique developed by Siltanen appears to be used in pointer-based interior architecture AR implementation. With this technique, the tissues around the objen are fused with the tissues in the area where the object is located, making the visual suitable for AR application (Siltanen, 2015). 


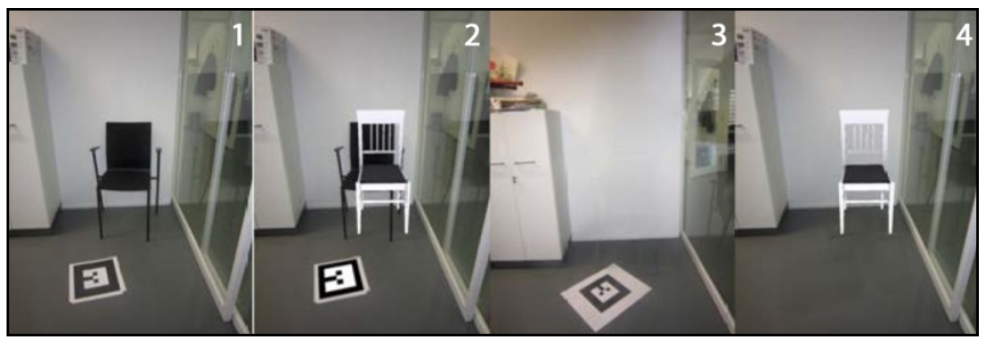

Figure 1.4.. An example of a diminished reality technique in AR. 1. Original visual 2 . AR process on existing object 3 . Implementation of the diminished reality technique. 4. Implementation of AR on diminished reality (Siltanen, 2012).

\section{Existing Interior Architecture AR Application Examples}

The use of AR technology in interior design is still very new. For this reason, the applications developed for interior design are mostly for entertainment purposes and do not concern any commercial concern. In addition to this, there are also some interior architectural AR applications developed for end users today that are not fully mature. Many of these applications promise users that they can buy branded furniture and decoration products that they test internally with AR technology, by seeing features such as material, size, color and texture. All of these applications share some commonalities with different characteristics, advantages and disadvantages. The applications of 'Decolabs', 'Ikea AR', 'Intiaro', 'Fingo', 'View AR', 'Houzz' and 'I Staging' which are developed for commercial purposes were examined from the point of use of AR technology .

\subsection{Decolabs}

Decolabs was developed in 2012 and is an interior architecture AR application where users can experience virtual furniture with an online catalog. This application not only allows the virtual furniture to be experienced in the real space, but also provides the opportunity to access the drawings of various residential spaces created with Decolabs products. Besides, users can test the virtual furniture on the visuals by uploading the photograph of the places they live in (URL-2, 2018). Virtually added furniture can be adorned with the help of a standard marker provided by the program. The program does not provide any flexibility in setting the size of the furniture to the user. In addition to this, the online brands include limited and concept design products. Users also have the opportunity to share their AR designs online. It is also foreseen that the space is relatively empty for flexible use of the program and that there is no obstacle in the field where the marking is placed for the AR technology to work properly. The application only supports the IOS platform for mobile devices. 


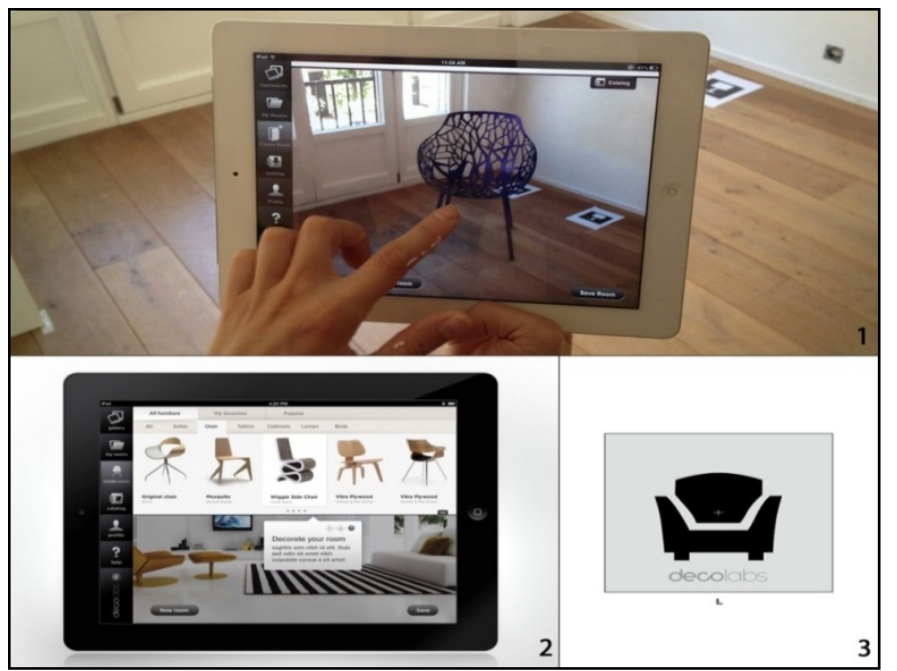

Figure 2.1. "Decolabs" AR application 1. Real-time interface of the program

3. Program product interface 3 . The marker provided by the program (URL-3, URL-4, 2018)

\subsection{Ikea AR}

Ikea AR is a software application starting in 2014 that is distributed to the users in an integrated manner to the company's mobile application. Users can visually test the decorative products and furnitures in their catalogs published by the company during the period with the help of AR technology. The application is only for the products of Ikea, so there is no connection with the product catalog of any other brand. The user can see the products he wants to test with all the features and can change the options such as the color and texture provided by the company (URL-4, 2018). Because Ikea has a widespread store network on a global scale, the speed and possibilities of obtaining a product that the user tests in the application of AR are relatively higher. In this application, it is also necessary that the relevant part of the space where the user is to test the products is empty or there is not a visual obstacle to obstruct the marking. The app, which has mobile app options for Android and IOS platforms, uses turnkey publishing catalogs as a marker.

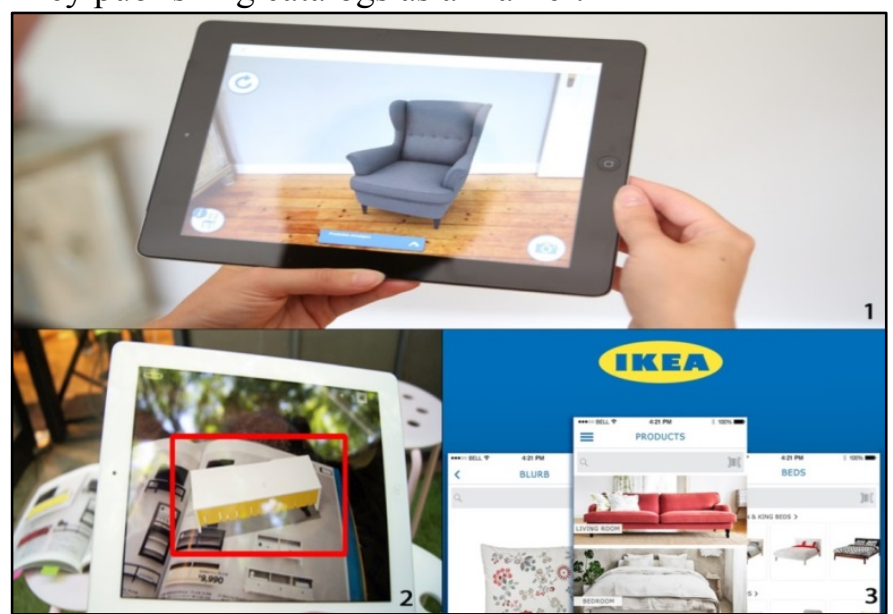

Figure 2.2. "IkeaAR" AR application 1. Real-time interface of the program

1. The catalog used as a program marker 3. The program's content interface (URL-5, 2016)

\subsection{Intiaro}

The Intiaro AR application has also been developed as an application where users can buy and sell reinforcements and decoration products with many brands support. In addition to grouping products 
such as seats, cabinets, and chairs in the application, there are many products within general spatial classifications such as hotel, living area, dining room. The user can carry out the desired product characteristics to the extent determined by the retail company and at the same time get information about the product's price, material, style and where to buy it. The fact that the product catalog has a simple use and it is important to be able to connect with social media so that users can share their designs in the social media environment. In addition, many of the products are also represented by real-world appearances (URL-6, 2018). In application, virtual products added to the space come in a standard size depending on the category. However, the fact that some products are normally large and that there is no means of adjusting the size of the products in application can be a problem for the health of the AR experience. On the other hand, the presence of retail companies in different countries constitutes an obstacle to the user's easy access to the product. This also indicates that additional shipping charges may be added to the price of the product. The application uses a standard visual marker with black and white contrasting colors. This interior AR application also predicts that the area in which the virtual soil will be placed is empty. Any real object found in the camera view angle collides with the virtual object, causing the occlusion problem. Users of both Android and IOS platforms are able to access the app.

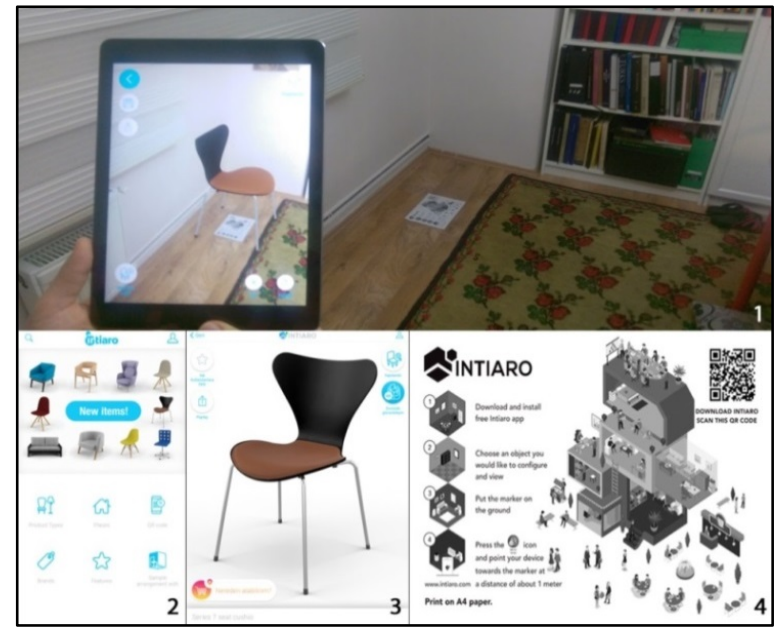

Figure 2.3. "Intiaro" AR application 1. Real-time interface of the program 2. Product catalog interface 3 . Visualization of the virtual image in the program 4. The marker used by the application (Photographs by Tolga Kılıç)

\subsection{Fingo}

Fingo AR application is also user-oriented applications developed for commercial purposes such as other internal architecture AR applications. The products included in the application are classified according to their intended use as they are in other applications. In this application, users can view properties such as product's material and price (URL-7, 2018). Although a wide variety of brand names appear in the program interface, many of the furniture that the user views in front of the AR experience do not reach the 3D model. Moreover, there are some problems related to the size of the product when it is displayed indoors. There is no intervention tool to adjust the size of the virtual product that is transferred to the actual space in a standard size. The program only uses two basic options such as displacement and rotation. The AR application uses a standard pointer to follow. However, the integration of the virtual object and the product is lost when the screen is moved, and the product deviates towards other directions. The same situation can also arise in the form of sticking virtual object to real objects during imaging. These adverse events affect the success of the AR process and severely limit its effectiveness. 


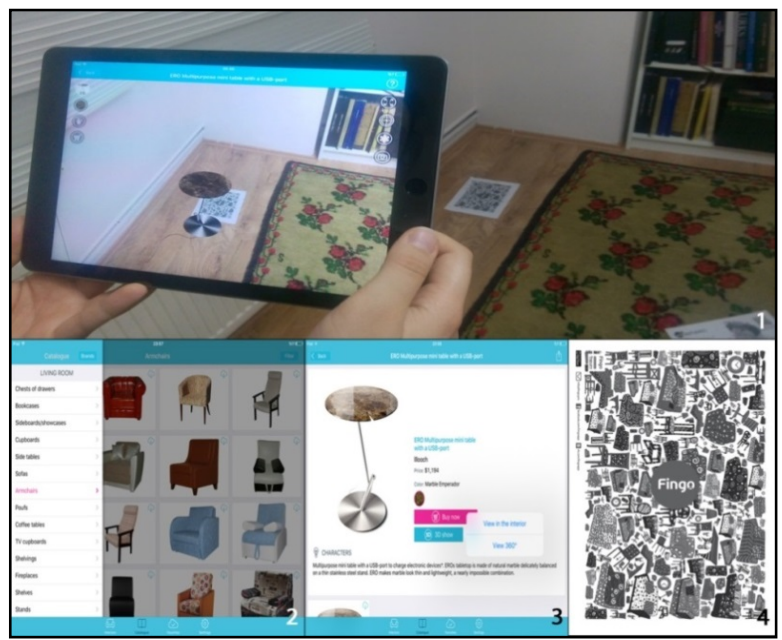

Figure 2.4 "Fingo" AR application 1. Real-time interface of the program

2. Product catalog interface 3. Visualization of the virtual image in the program

\subsection{ViewAR}

4. The marker used by the application (Photographs by Tolga Kılıç)

The "ViewAR" interior architecture is an application developed by means of the "ViewAR SDK". Allowing users to develop their own applications with open source online software, the ViewAR SDK also enables application development for different areas (URL-8, 2018). It is seen that the number of commercial firms in ViewAR is lower than the number of firms in other AR applications. The application works by downloading and displaying the product model desired by the user connected from the online connected server in the application. However, waiting and loading times can be increased compared to the type of downloaded model. In addition to performing AR application during live scene streaming, the application also offers the user the option of freezing the displayed scene. This allows the user to obtain more stable images. The user can change the pattern of the downloaded model and the rate of the options offered in the color. There are frequent alignment and sizing problems in the running application without using any pointers. As a result, virtual images are floating on the actual space. The alignment and tracking system, which is crucial for an AR application, negatively affects the AR experience. Compared to the positive and negative aspects, ViewAR is more like entertainment than a commercial indoor AR application.

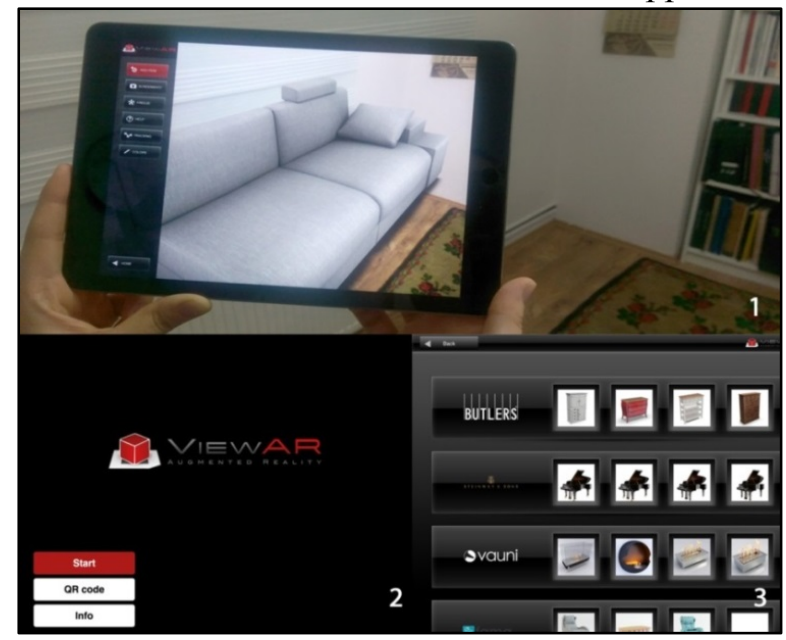

Figure 2.5. "ViewAR" AR application 1. Real-time interface of the program 2. Basic application menu 3. Virtual product catalog (Photographs by Tolga Kılıç) 


\subsection{Houzz}

As a comprehensive decoration application, Houzz has a wide range of design products and market links within its territory (URL-9, 2018). In this mobile application, decoration items used indoors are classified according to the places where they are used. Another detail that draws attention in application is the use of photographs of places where the accessories are sold. By tapping on these photos, the user can see the properties and the price of the corresponding accessory element and display them virtually. In application, the product can be ordered on the fly, comments from other users can be seen, and the related store can ask questions about the product. It is not possible to display all of the products in the application with the AR technique. This is a negative point in terms of AR experience. In application, three dimensional non-virtual products can be placed in two dimensions. In the Houzz AR application, the placement of virtual products and the adjustment of the dimensions of the products is a challenging process. The reason for this is that the application does not use any marker tracking technique. For this reason, the angle that the user wants is open and must make a great effort to capture the size. Since there is no diminished realistic feature in the application, it is foreseen that the area where the virtual object will be placed is empty. When the camera of the mobile device is rotated and restored during the AR application, virtual furniture loses its position by swimming in the air. Houzz can be regarded as a relatively rich and serious but AR-oriented application in terms of product and brand variety.

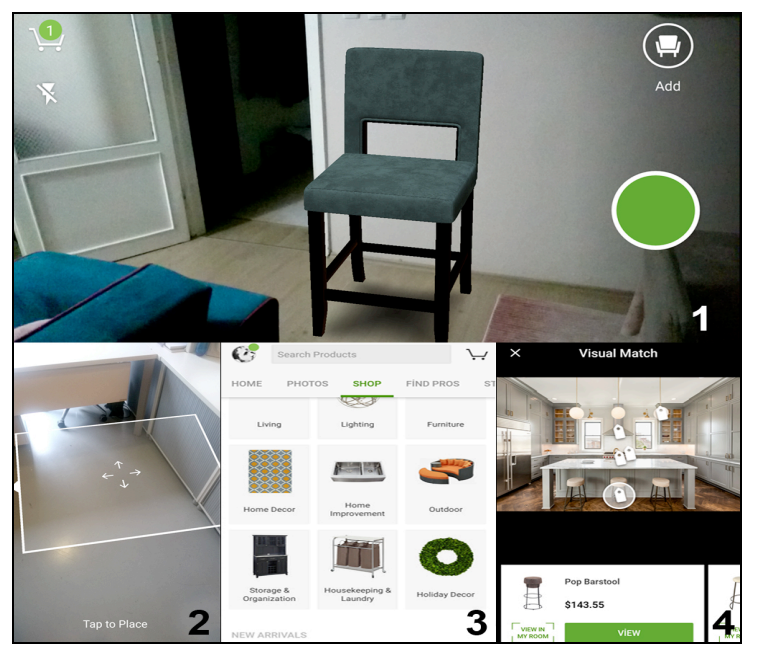

Figure 2.6. "Houzz" AR application 1. Visualization of virtual object

2. Installation of virtual object 3. Interface of program

4. Ability to select furniture by photo (Photographs by Tolga Kılıç)

\subsection{IStaging}

Istaging is a commercial mobile AR application developed for the end user, which does not contain only the accessory component (URL-10,2018). Products in application are classified by type of space, type of products and brands. At the same time, users can search for the desired product or brand with the search function found in the program interface. Users can order products that they like through the application. The program has a relatively easy interface. The accessories can be experienced in different colors and textures of the products of the companies. In addition, the products can only be displayed in three dimensions. However, it would be appropriate to state that the application appears to be weak in terms of product diversity. Users can add favorite products to the list of favorites and list past orders. All products in the application can be displayed in the room with AR principle. At this time, the user can take the picture of the virtual object which is located in the space and share it in the social media. It is estimated that the photorealism level of the products is sufficient. The absence of a 
visual marker in the application causes the virtual object to be displayed in an unstable state. On the other hand, during the placement of the virtual object in the interior space, the size can be adjusted according to the person and the space and can be placed at the desired place. This is a remarkable feature as a positive feature. In application, when the camera is moved and the virtual object is outside the camera angle, the object position is lost. The program also does not have a diminished reality feature that would allow the existing equipment to be lost. As a result, Istaging, which has an easy-touse interface, enables users to experience an AR experience with less effort.

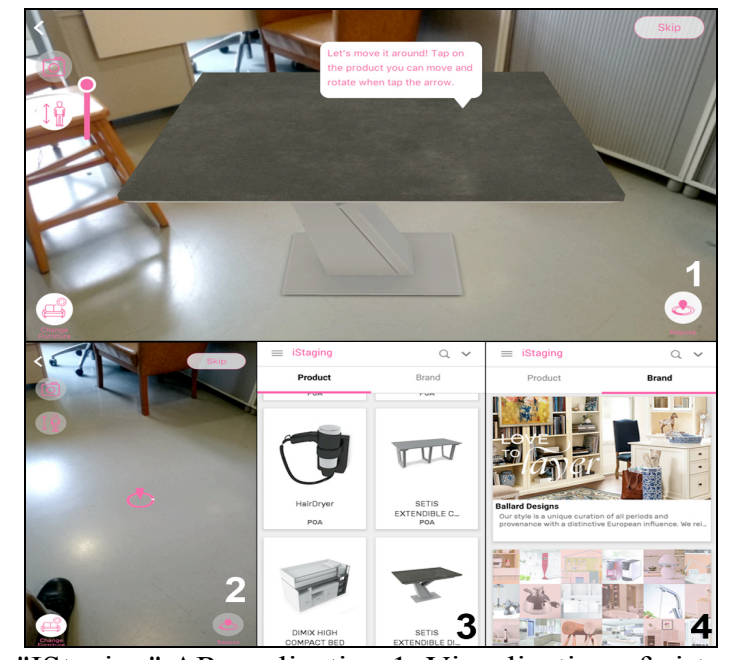

Figure 2.7. "IStaging" AR application 1. Visualization of virtual object

2. Installation of virtual object 3 . Interface of program

4. Classification of products in the program interface (Photographs by Tolga Kılıç)

\begin{tabular}{|c|c|c|c|c|c|c|c|c|c|c|c|}
\hline APPLICATION & Platform & $\begin{array}{l}\text { Tracking } \\
\text { System }\end{array}$ & $\begin{array}{c}\text { Space } \\
\text { Modeling } \\
\text { Option }\end{array}$ & $\begin{array}{c}\text { Usage } \\
\text { Interface }\end{array}$ & $\begin{array}{c}\text { Virtual } \\
\text { Ooject } \\
\text { Size Control }\end{array}$ & $\begin{array}{l}\text { Virtual Object } \\
\text { Color and } \\
\text { Tissue Control }\end{array}$ & Photorealism & $\begin{array}{l}\text { Interaction } \\
\text { with Existing } \\
\text { Furniture }\end{array}$ & $\begin{array}{l}\text { Trademark } \\
\text { Support }\end{array}$ & $\begin{array}{l}\text { Social Media } \\
\text { Support }\end{array}$ & $\begin{array}{l}\text { Operation } \\
\text { Recordability }\end{array}$ \\
\hline Decolabs & IOS & $\begin{array}{l}\text { Visual } \\
\text { Marker }\end{array}$ & Yes & Easy & Yes & Yes & High & No & Limited & Yes & Yes \\
\hline Ikea AR & IOS/Android & $\begin{array}{l}\text { Visual } \\
\text { Marker }\end{array}$ & Yes & Easy & No & Yes & Normal & No & High & Yes & Yes \\
\hline Intiaro & IOS/Android & $\begin{array}{l}\text { Visual } \\
\text { Marker }\end{array}$ & No & Easy & No & Yes & High & No & High & Yes & Yes \\
\hline Fingo & IOS & $\begin{array}{l}\text { Visual } \\
\text { Marker }\end{array}$ & No & Normal & No & No & Normal & No & Limited & Yes & No \\
\hline View AR & IOS/Android & No Marker & No & Easy & No & Yes & High & No & Very Limited & No & No \\
\hline Houzz & IOS/Android & No Marker & No & Hard & Yes & Yes & High & No & High & Yes & Yes \\
\hline I Staging & IOS/Android & No Marker & No & Hard & Yes & No & High & No & High & Yes & Yes \\
\hline
\end{tabular}

Table 2. Table prepared to reveal the activities of the existing interior AR applications examined.

(Table: Tolga Kılıç)

\section{Evaluation of the examined applications}

Table 2 shows the effectiveness, positive and negative aspects of existing AR applications developed for interior design. The table is based on the current situation of the applications dated 18.02.2018. The main criteria set out in the table were determined in accordance with the mind map in Table 2.1, 
which emerged as a result of the field survey by Siltanen and his team. These criteria are; It is the option of modeling the space, using interface, interacting with the size and color and texture of the virtual objet, photorealism, interacting with existing furniture, trademark support, social media sharing feature and working.

According to this table; five of the seven apps surveyed support both the IOS and Android platforms. The remaining two applications only work on the IOS platform. The four applications studied are based on the visual marker tracking system. The other three applications do not use any markers. While Decolabs and Ikea AR from AR applications have a feature to create a space from scratch, other applications do not have this feature. It has been understood that the interfaces of applications other than Fingo and Houzz are relatively easy to use. Fingo, on the other hand, looks a bit more complicated than that. Applications other than Decolabs, Houzz and Istaging do not allow the user to change the dimensions of the furniture placed in the room. The color and texture of virtual accessory elements can be changed in all applications except Fingo. On the other hand, five of the applications have high photorealistic furniture models, while Fingo and Ikea AR are a bit back at this point.

Another option with a user-definable feature is the ability to place virtual furniture in place instead of deleting existing furniture. This feature is not available in any AR application being examined. Since this feature is not available, the part of the space where the AR is to be applied must be empty. All of the applications work in connection with retail furniture companies. Fingo, View AR, Decolabs and Istaging applications provide access to a very limited number of company products. In this case it has a restrictive effect on the effectiveness of the application. At this point, Ikea only allows users of their product range to experience the model. But Ikea is one step ahead of other applications because it is a global brand and has a very common store network. Intiaro and Houzz applications are also attracting attention as AR applications with broad brand support. In other applications besides Ikea, Houzz and IStaging applications examined applications, orders are made by paying a favored model from a menu in the application and invoiced by following this order. There is no such option. This is a major deficiency as well. In all applications except View AR, users can share photos from their social media accounts by pulling the photos of the virtual furniture they have placed in their homes. Since Decolabs and Ikea applications give users the opportunity to create a space from scratch, they then offer the option to save the scene so they can revise these projects. In other applications, such an approach is not available.

As a result of examination of interior AR applications; it has been found that there is no internal application of AR which is user-friendly and widely available, which provides all of the basic features mentioned above. Although some applications are ahead in terms of the features they have, it has been understood that it will take some time for their development to be completed and to reach the user's satisfaction point. It will not be a mistake to say that new applications of AR applications in the light of technological developments in the forthcoming period will have the ability to use indoors and have great potential at this point.

\section{CONCLUSION}

Within the scope of the study, the importance of effective use of the AR technology by the user has been mentioned. In this context, seven user-centric internals have been examined on the IOS and Android platform in terms of functionality of the AR application. In the light of the survey, it is understood that individual users need a simple, fast, user-friendly, customizable, wide-ranging AR application. However, none of the AR applications examined has exactly these features. Some applications have limited model libraries, while others are insufficient in brand support. Applications that are relatively understandable by user interfaces do not allow the virtual model to be experienced in a place with things, even a blank field cannot work consistently. For these reasons, these 
applications cannot go beyond just doing recreational experiments. All of these evaluations have shown that the need for a mobile indoor AR application, which offers easy user interface, easy integration of local brands, virtual support of the furniture, and user support to the ordering stage. However, it is expected that individual users will also have the ability to destroy the object at the place where the virtual model will settle, since they will use the AR application in the places where the objects are located. Besides, it has been seen that the display of an interior fitting or decoration component in the room has the potential to change the retail sales habits. If the end-user can easily apply decorative revisions at home through an effective AR application, this can strongly influence the sector. The furniture retailer can introduce new products through an AR application, reduce the return rate, increase product sales and create a new customer portfolio. At this point it has been seen that developing a healthy interior AR application is also important in terms of furniture retailer.

The effective use of AR technology indoors is thought to strongly influence the real estate industry. Users can view the furnished condition of the houses they want to rent or buy or the interventions for design simultaneously with AR. Even different concept designs and venues arranged with different goods can be represented by AR and alternative design approaches can be presented to the customers. It has been observed that some technical problems need to be overcome in order to enable the AR applications to operate indoors in a healthy manner during the operation. At the beginning of these problems is the correctness of the identification and follow-up mechanisms. This issue is especially important for indoor applications. In today's systems, the quality of the internal AR experience drops as the quality of the system decreases after a certain distance. In the future, it is thought that mobile AR systems with camera with space depth detection will experience a more positive experience for the user by analyzing the characteristics of the space.

In the framework of all these evaluations, the use of AR technology in interior design and presentation will be a very effective method in the future. AR, a new generation of digital technology, will still close this gap with technological achievements in the near future, although it still has some limitations. AR is one of the technologies that will play a leading role in transforming the concept of space into human benefit if it is used correctly with its design applications.

\section{REFERENCES}

Azuma, RT., 1997. A survey of Augmented Reality. Presence: Teleoperators and Virtual

Environments, Boston: MIT Press, 6, pp. 355-385.

Caarls, J., Jonker, P., Kolstee, Y., Rotteveel, J., Eck, W., 2009. Augmented Reality for Art, Design and Cultural Heritage-System Design and Evaluation, EURASIP Journal on Image and Video Processing20092009:716160 https://doi.org/10.1155/2009/716160.

Cowan, P., \& Butler, R. (2013). Making geography mobile: using location aware technology to improve student performance in physical geography. Journal of Research and Didactics in Geography, 1(2), 85-105.

Craig, A. B., 2013. Understanding Augmented Reality: Concept and Applications, Elsevier Science, USA.

FitzGerald, E., Ferguson, R., Adams, A., Gaved, M., Mor, Rhodri, Y., ve T., 2013. Augmented reality and mobile learning: the state of the art. International Journal of Mobile and Blended Learning, 5(4) pp. 43-58.

Furth B., 2011. Handbook of Augmented Reality, Springer Science+Business Media Heidelberg, London. Francis, D., Ching, K., 1987. Interior Design Illustrated, USA.

Luckin, R., Stanton Fraser, D., 2011. Limitless or pointless? An evaluation of augmented reality technology in the school and home. International Journal of Technology Enhanced Learning, 3(5), 510-524. doi:10.1504/IJTEL.2011.042102. 
Specht, M., Ternier, S., Greller, W., 2011. Dimensions of Mobile Augmented Reality for Learning: A First Inventory, Journal of the Research Center for Educational Technology (RCET) Vol. 7, No. 1, Spring 2011 RCETJ 7 (1), 117-12.

Milgram, P., Takemura H., Utsumi, A., Kishino, F., 1994. Augmented Reality: A Class of Displays on The Reality-Virtuality Continuum, SPIE 2351, Telemanipulator and Telepresence Technologies pp. 282-292, Japan.

Munnerley, D., Bacon, M., Wilson, A., Steele, J., Hedberg, J., \& Fitzgerald, R., 2012. Confronting an augmented reality. Research in Learning Technology, 20, 1-10. doi:10.3402/rlt.v20i0.19189.

Rohs, M., Schöning, J., Krueuger, A., Hecht, B., 2007. Towards Real-Time Markerless Tracking of Magic Lenses on Paper Maps, Adjunct Proceedings of the 5th Intl. Conference on Pervasive Computing (Pervasive), Late Breaking Results, pp. 69-72.

Schall, G., 2013. Mobile Augmented Reality for Human Scale Interaction with Geospatial Models The Benefit for Industrial Applications, Springer Gabler.

Siltanen, S., Oksman, V., User-Centered Design of Augmented Reality Interior Design Service, 2013. International Journal of Arts \& Sciences, 6, 1, pp. 547-563., Finland.

Siltanen, S., 2015. Developing Augmented Reality Solutions Through User Involvement, Thesis for the degree of Doctor of Science in Technology, Aalto University School of Science, Department of Computer Science, Finland.

\section{INTERNET RESOURCES}

1- https://www.gartner.com/smarterwithgartner/top-trends-in-the-gartner-hype-cycle-for-emerging-technologies2017/ Date of Access: January/2018

2- https://static2.teknoblog.com/wp-content/uploads/2017/11/amazon-ar-view-021117-1.jpg Date of Access: January/2018

3- http://www.decolabs.com/ Date of Access: January/2018

4- http://www.adrienjeanjean.com/content/decolabs/poster.jpg Date of Access: January/2018

5- http://www.sasachen.com/ikea/ Date of Access: January/2018

6- https://www.intiaro.com/ Date of Access: January/2018

7- http://fingo.pro/en/ Date of Access: January/2018

8- http://developer.viewar.com/site/home Date of Access: January/2018

9- https://www.houzz.com/ Date of Access: February/2018

10- https://www.istaging.com/en/Date of Access: February/2018 